\title{
BAJO LA MISMA LUNA: LA SIMBOLOGÍA DE LA LUNA EN LI BAI Y FEDERICO GARCÍA LORCA
}

\author{
UNDER THE SAME MOON: THE SYMBOLOGY OF THE MOON \\ IN LI BAI AND FEDERICO GARCÍA LORCA
}

\section{Rubén Jesús ALMENDROS PEÑARANDA}

Universidad de Granada ${ }^{1}$

\begin{abstract}
Resumen: El presente estudio tiene como objetivo el análisis de la simbología de la luna en las obras literarias del poeta chino Li Bai y del escritor español Federico García Lorca. A partir de la lectura de una selección de textos determinaremos cómo la tradición cultural propia de cada autor $-\mathrm{y}$ concretamente la simbología convencional de la luna - resulta determinante en la formación de Li Bai y de Federico García Lorca para transgredir las leyes de la tradición y buscar innovaciones en el terreno metafórico.
\end{abstract}

Palabras clave: Federico García Lorca; Li Bai; literatura china; luna; símbolo; metáfora.

Abstract: The aim of this study is to analyze the symbology of the moon in the literary works of the Chinese poet Li Bai and the Spanish writer Federico García Lorca. From the reading of a selection of texts, we will determine how the respective author's cultural tradition - and particularly the conventional symbology of the moon- determines their transgression of the traditional norms and innovations in metaphor theory.

Keywords: Federico García Lorca; Li Bai; Chinese literature; symbol; metaphor.

\footnotetext{
${ }^{1}$ El presente artículo se ha llevado a cabo gracias a una Beca de Iniciación a la Investigación otorgada por el Vicerrectorado de Investigación y Transferencia de la Universidad de Granada (UGR).
} 


\section{$\mathbf{I}$}

ntroducción

A lo largo de los siglos han sido muchos los artistas que han contemplado el cielo en búsqueda

de inspiración. Ya fuera en el Viejo Continente, en las Américas o en el Asia Oriental el ser humano se ha dejado maravillar por un espectáculo nocturno regido por la luna, astro al que hemos confiado la expresión de nuestros sentimientos más profundos. La luna se ha convertido así en un tópico recurrente en la obra literaria de incontables artistas sin importar su cultura de procedencia o la época histórica en la que se insertan.

Bajo esta premisa, nos preguntamos por la necesidad de otro proyecto de comparación literaria, como el que aquí se va a presentar, que tenga como eje vehicular un símbolo tan universal y estudiado como es la luna. A esta cuestión debemos sumar el hecho particular de que los dos artistas que aquí se analizarán —el poeta chino Li Bai (700-762) y el escritor español Federico García Lorca (18681936) - no son autores próximos ni geográficamente ni en el tiempo. Además, a pesar de que la obra lorquiana sí estuvo fuertemente marcada por el orientalismo de la Europa del siglo XIX, no podemos advertir una influencia directa del admirado poeta de la dinastía Tang en García Lorca. No son tan siquiera los únicos literatos que, en sus respectivas culturas, han optado por la luna como protagonista de sus textos - aunque sí quizás los más representativos-. Por tanto, ¿cuál es el valor y, a la vez, objetivo principal del presente ensayo?

La elección de Li Bai y Federico García Lorca como elementos de nuestra comparación parte de una hipótesis central: el tratamiento de la luna como símbolo por parte de cada uno de estos autores supone una revolución respecto a la tradición anterior. Nuestro propósito es, en definitiva, estudiar cómo la tradición cultural propia de cada autor - y concretamente la simbología convencional de la luna- resulta determinante en la formación de Li Bai y de Federico García Lorca para transgredir las leyes de la tradición y buscar innovaciones en el terreno metafórico.

Para ello, estructuraremos este trabajo en dos grandes bloques, precedido de un breve estudio intercultural sobre la metáfora. En primer lugar, situaremos a Li Bai y a García Lorca en sus tradiciones literarias como autores a caballo entre la perpetuación de lo clásico y la búsqueda de lo vanguardista. Una vez estudiado el contex to histórico-literario de cada artista, procederemos al análisis comparativo de sus obras a partir de la simbología de la luna, entendida como conjugación de tradición e innovación. Para la ejemplificación emplearemos la compilación de la obra de Lorca editada por Arturo del Hoyo (1954) y la antología bilingüe de Li Bai realizada por Anne-Hélène Suárez (2005). 


\section{La metáfora en la cultura china y occidental ${ }^{2}$}

La metáfora se define como una figura retórica que consiste en la sustitución de un elemento real por otro imaginario con el que guarda una relación de semejanza. La metáfora, por tanto, es un tropo que va más allá de una mera transferencia o sustitución y que está estrechamente vinculado a la poética grecolatina. Recordemos que Platón condenaba el arte en su República alegando un carácter mimético ${ }^{3}$. Aristóteles, por el contrario, ensalzaba la figura del poeta, al que consideraba un hacedor, dada su labor de imitación de las acciones de los hombres, tanto buenos como malos. ${ }^{4}$

Más tarde, la cosmología judeocristiana concebirá un universo dualístico, basado en la contraposición de lo concreto y lo abstracto, de lo particular y lo universal, y que encuentra su máxima representación en la idea de Dios — de naturaleza abstracta, pero transmutable en el mundo sensibleEn este sentido, la metáfora, que presenta afinidades entre mundos distintos, es creadora de verdades universales.

La metáfora, pues, encuentra su fundamento en la disparidad entre el significante y el significado. El placer estilístico resultante se debe al desvío del uso común del lenguaje y a su carácter indirecto. En el Renacimiento la metáfora se considerará el ornamento estilístico supremo y ya en el Romanticismo se equiparará el estatus de la metáfora al de la misma poesía. Incluso autores contemporáneos otorgarán un rol privilegiado a la metáfora: Paul Ricœur, por ejemplo, se refiere a ella como mímesis de la lexis, que asimila a la propia poesía (mímesis es poiesis y viceversa). ${ }^{5}$

En resumen, la metáfora, en tanto que modo cognitivo, permite conectar una imagen con una idea, alcanzar lo inteligible a través de lo sensible, trazar una representación que trasciende a una verdad. Por su misma naturaleza, la metáfora es un recurso poético propiamente europeo y, por extensión, occidental. Es por ello que emplear el término "metáfora" stricto sensu en los estudios sobre poesía clásica china no es del todo apropiado.

Con el fin de arrojar un poco de luz sobre la terminología metaliteraria en China, acudimos al Gran Prefacio de Mao (Mao Daxu 毛大序). Este comentario que sirve de prólogo al Clásico de la poesía (Shijing 詩經) hace referencia a tres modos de expresión literaria: la exposición ( $f u$ 賦), el símil ( $b i$ 比) y la asociación o motivo (xing 興). Dado que el fu consiste en una descripción exhaustiva sobre un tema concreto, nuestro dilema sobre el correspondiente chino de la metáfora occidental gira en torno a los otros dos modos bi y xing.

Tanto bi como xing implican una comparación. Mientras bi hace referencia a las palabras utilizadas por analogía, el modo xing comprende todas las expresiones que incitan una reacción en el

\footnotetext{
${ }^{2}$ En estas páginas el término colonialista “occidental”, a pesar de su imprecisión, nos sirve para hacer referencia a todas aquellas culturas que beben de las tradiciones grecolatina y judeocristiana.

3 «Si [el poeta] tuviera realmente conocimiento de aquellos objetos que imita, se afanaría mucho más por trabajar en ellos que en sus imitaciones, trataría de dejar muchas y hermosas obras como monumentos de sí mismo y ansiaría ser más bien el encomiado que el encomiador» (Platón, 2015: 634).

4 «Los imitadores imitan a sujetos que obran, y éstos por fuerza han de ser o malos o buenos. [...] Tal es también la diferencia que hay de la tragedia a la comedia; por cuanto ésta procura imitar los peores, y aquélla hombres mejores que los de nuestro tiempo» (Aristóteles, 1976: 27).

5 «No cabe mímesis más que donde hay un hacer» (Ricœur, 1980: 61).
} 
lector. La diferencia entre bi y xing, por tanto, es comparable a nuestra distinción entre un tropo y un símbolo. En un tropo la semejanza entre los dos elementos es indispensable. En cambio, la contigüidad, y no la similitud, es la propiedad central de un símbolo, lo que implica que esté más basado en la asociación y la evocación que el tropo. Por esta razón, mientras que en un tropo las dos partes de la comparación aparecen explícitas y tan solo presentan un significado figurativo, en el símbolo únicamente uno de los dos elementos aparece en el texto y actúa no solo metafóricamente, sino también literalmente ( $c f r$. Wang, 1992: 178).

Trasladando este principio teórico a la literatura china, concluimos que el modo xing se comporta como una fórmula que despierta en el lector una serie de emociones que el poeta identifica con un motivo determinado, externo al texto, tal y como funciona el símbolo. Por el contrario, el $b i$ insiste en la afinidad entre los dos elementos, que aparecen explícitos en el texto, de forma similar al mecanismo metafórico.

Ahora bien, Pauline Yu ( $c f r$. 1981: 208) se percata de la sutil diferencia entre la metáfora occidental y el concepto $b i$, dado que en numerosos estudios sobre poesía clásica china se incluyen yuxtaposiciones y personificaciones bajo el nombre de metáforas. Concretamente, en la poesía de Li Bai la luna es descrita en numerosas ocasiones a través de yuxtaposiciones, en las que ambos elementos de la relación están presentes en el texto. Por ejemplo, en «Canto de Qiupu XIII» (Li Bai, 2005: 37) se evoca una «luna pálida» (suyue素月), recurso estilístico en el que no advertimos la relación “A es B" (la luna es la palidez), base de toda metáfora, sino un epíteto, resultado de la yuxtaposición de dos elementos. En cambio, si atendemos al poema de García Lorca «Romance de la luna, luna» (García Lorca, 1954a: 393-394), comprobamos la presencia de metáforas como «mi blancor almidonado», que sustituye a la luna en tanto que término imaginario.

A modo de conclusión, explicaremos brevemente las principales diferencias entre la metáfora occidental y el $b i$ chino. Si en la metáfora advertimos una divergencia entre las dos imágenes, una real y otra imaginaria; el modo bi asume la complementariedad de la correspondencia, es decir, el $b i$ establece una afinidad entre dos elementos del mundo orgánico. Mientras la metáfora genera un nuevo conocimiento gracias a la creatividad del poeta, el bi reitera las conexiones entre los elementos siguiendo un patrón holístico y supone una extensión de ejemplares ya conocidos. Por último, la metáfora se basa en la comparación y el contraste entre el término real e imaginario. El bi chino, en lugar del contraste característico de la metáfora, explicita la correlación entre los elementos y crea, en consecuencia, una experiencia unificada entre lo humano y lo natural ( $c f r$. Yeh, 1987: 250-251).

Una vez resueltas estas cuestiones teóricas previas, conviene advertir que, en un esfuerzo de asimilación, se optará por emplear en este trabajo la terminología occidental a la hora de analizar tanto la obra de Li Bai como de García Lorca. Es decir, utilizaremos los conceptos de metáfora y símbolo en vez de los términos chinos bi y xing. ${ }^{6}$

\footnotetext{
${ }^{6}$ Dada la ingente literatura disponible en torno al debate entre la metáfora occidental y los modos chinos, recomendamos una serie de lecturas que ayudan a dilucidar este debate. En relación a los vínculos entre metáfora y bi, destacamos el trabajo de Yu-Kung Kao y Tsu-Lin Mei titulado «Meaning, metaphor and allusion in T’ang poetry» (1978) y la magnífica refutación de Pauline Yu en «Metaphor and Chinese poetry» (1981). En lo que respecta a las implicaciones del modo chino
} 


\section{Li Bai en su contexto literario}

La dinastía Tang (618-705) es considerada como la Edad de Oro de la poesía clásica china. Los años de reinado del emperador Xuanzong (712-756) son especialmente relevantes en literatura, puesto que coinciden con el periodo de apogeo de los que, según la crítica, son los mejores poetas chinos: Li Bai (李白, 700-762) y Du Fu (杜甫, 712-770). Esta es la primera vez que en la literatura china encontramos un grupo con una estética unificada a partir de la cual cada poeta alcanza su propia individualidad.

Li Bai es un autor muy peculiar que conformó un nuevo concepto de genio literario. Escribía rápido y en grandes cantidades, se consideraba a sí mismo un inmortal y, a pesar de ser un gran conocedor de su tradición, obvió la autoridad y la costumbre en su propósito de alcanzar una libertad creativa insólita en otros poetas. De hecho, tal es su personalidad transgresora que, según ciertas fuentes, rechazará la carrera funcionarial, aun habiéndose formado en una educación clásica.

En lo que respecta a la perpetuación de la tradición poética, Li Bai cultiva el estilo antiguo (古 詩 gushi), tal y como evidencia su colección de cincuenta y nueve “aires” (古風 gufeng). Están en gran medida influidos por Chen Ziang (陳子昂, 661-702), autor de la dinastía Tang, y sus ganyu (感遇), poemas de carácter taoísta escritos con un vocabulario simple.

Aparte de los gufeng, Li Bai compondrá numerosas canciones populares o yuefu (樂府). El estilo $f u$, ampliamente desarrollado por la Oficina de la Música durante la dinastía Han, se inspira en melodías antiguas y supone una quinta parte de la producción poética total de Li Bai. Entre todas las temáticas posibles, nuestro poeta muestra especial predilección por una tradición muy antigua dentro de los yuefu: las canciones de añoranza (有所思 yousuosi). Aunque en sus poemas persisten los códigos fijos de este tipo de composiciones nostálgicas (el otoño, la escarcha, la luna, las cortinas, etc.), Li Bai no duda en introducir componentes innovadores.

Esta faceta rompedora de Li Bai es la que nos resulta más interesante. En el terreno formal, Li Bai cultivó el estilo moderno o regulado (近體詩 jintishi), representado por las cuartetas (絕句 jueju) y los poemas regulares o lüshi (律詩). Dentro de este estilo Li Bai transgredió en muchas ocasiones las reglas establecidas: por ejemplo, en los lüshi se tomó algunas licencias como la introducción de repeticiones y la utilización o elisión de paralelismos.

Ahora bien, sus aportaciones son especialmente relevantes respecto al contenido. Owen ( $c f r$. 1981: 121) define la capacidad inigualable de Li Bai como "imaginación ficcional”. Hasta el momento, para tratar un tema histórico, los poetas optaban por una meditación ocasionada por la visita a un lugar antiguo en torno a la que giraba toda la composición. En cambio, Li Bai, bajo una nueva concepción poética, especulará brevemente sobre el pasado del espacio histórico en cuestión para luego dar paso al eje central del texto: el presente del poeta, es decir, lo que el autor ve, siente e imagina.

En este sentido, advertimos en la obra de Li Bai una conciencia explícita del autor en tanto que creador. Este concepto encuentra su antecedente en la obra de Sima Xiangru (司馬相如, 179-119 a.C.),

xing, la tesis de Wang Nian En, «The Xing: A comparative approach to Chinese theories of the literary symbolic» (1992), resulta verdaderamente dilucidadora. 
autor de la dinastía Han, caracterizado por una exuberancia verbal y una imaginación especulativa sin precedentes. El gran legado de este poeta, especialista en $f u$, para la teoría literaria china es, según Lu Ji (陸機) ${ }^{7}$, su concepción cósmica sobre la naturaleza del arte literario: la conciencia del poeta aparece en sus obras estrechamente vinculada al orden del universo. Ahora bien, debemos ser cautos cuando rastreamos los antecedentes de la poesía de Li Bai, dada la mitificación que siempre ha rodeado a este poeta. Quizás sea la imagen de Sima Xiangru como conquistador nato y gran bebedor lo que interesa a Li Bai a la hora de crear un yo poético caracterizado por una ambigüedad moral evidente. Para no incurrir en el error de creer todas las anécdotas que componen su propio mito, es esencial disociar la biografía de su alter ego poético.

En relación a esta conciencia poética, Varsano ( $c f r$. 1992: 226-228) expone dos conceptos fundamentales para entender la revolución poética que supone Li Bai: la inmediatez y la alusión. Li Bai insta al lector a reconocer la diferencia entre la alusión presente en su poema y la verdadera referencia textual, más allá de la mera comprensión del significado de la alusión. De esta forma, se produce un efecto de inmediatez en dos planos. Por un lado, provoca un extrañamiento de la alusión al referirse explícitamente al pasado y asumir una universalidad, lo que lleva al lector a repensar el lugar común y sentir un efecto de espontaneidad y liberación de la actividad literaria. Por otro lado, la alusión conlleva a que el lector eleve su mirada a la del propio artista de manera que la voz de Li Bai se dibuje por encima de la misma tradición heredada. En definitiva, esta serie de recursos poéticos convierten a Li Bai en un poeta inmediato, que parece responder espontáneamente a unas simples guías de la tradición literaria. A partir de estas referencias al pasado Li Bai consigue introducir magistralmente su visión subjetiva.

Entre todas las convenciones poéticas rescatadas de la tradición y que logrará revolucionar cabe destacar el símbolo de la luna. Tal es la mitificación de Li Bai que incluso se ha creado una leyenda particular en torno a su muerte. Se dice que Li Bai, completamente ebrio, falleció una noche al intentar atrapar el reflejo de la luna en el agua mientras paseaba en barca. Esta anécdota, sin duda, expone a la perfección el interés casi obsesivo por la luna que Li Bai quiso atribuir a su yo poético. La luna se convierte frecuentemente en compañera inseparable del poeta a lo largo de toda su obra literaria.

\section{Federico García Lorca en su contexto literario}

La Generación del 27 se define habitualmente como un grupo literario español caracterizado por una tensión dialéctica entre la vanguardia y la tradición. Fuertemente influidos por el lenguaje poético de Góngora y por la literatura europea de vanguardia, estos escritores emprendieron una relectura de la tradición popular y culta desde ojos vanguardistas. Asistimos, pues, a una síntesis de lo tradicional y lo innovador en el propio seno de la vanguardia, siempre entendida como una celebración del

\footnotetext{
${ }^{7}$ Lu Ji (261-303) es un escritor chino que teorizó en su obra Wenfu (文賦) acerca del género fu, que floreció durante la dinastía Han.
} 
presente y el futuro. Bajo este propósito, la metáfora, concebida de forma autónoma al objeto estético, se convierte en un útil imprescindible para todos estos autores.

Son muchos los literatos de la Generación del 27 que reivindican la tradición popular, como Pedro Salinas, que elogia la llamada tradición "analfabética" (coplas, canciones infantiles, romances...), o Miguel de Unamuno, que fusiona la tradición culta y popular en su concepto de "tradición eterna". Sin embargo, si debemos destacar a un único autor que haya elevado la poesía popular a una categoría culta, ese sería sin duda alguna Federico García Lorca.

Federico García Lorca, ya desde joven, dedicó importantes esfuerzos a recopilar y documentar la literatura oral española, que más tarde estilizaría en sus obras bajo el modelo de Juan Ramón Jiménez. Si de Menéndez Pidal aprendió la búsqueda de lo tradicional auténtico y de un arte colectivo, en la obra musical de Manuel de Falla encontró la esencia del espíritu andaluz.

En su Charla sobre el Cante Jondo (1922), Lorca reivindica la herencia de Manuel de Falla y rescata la dignidad musical del canto primitivo andaluz, sintetizado en el cante jondo, así como la defensa del poder sintético de sus letras ${ }^{8}$. La pretensión de Falla era, en definitiva, elevar el arte tradicional a un estadio supranacional mediante la estilización individual y la depuración de elementos locales.

Siguiendo las pautas del compositor andaluz, García Lorca organizará en 1922 el Concurso de Cante Jondo, participará en la fundación del nuevo Ateneo en 1926, impulsará la revista literaria Gallo en 1928 y plasmará en su cancionero popular — interpretado por la Argentinita - la polifonía interior de la música popular granadina. En el terreno literario, Lorca renueva el romance, retoma las metáforas tradicionales y convierte a los gitanos en los depositarios del arte primitivo andaluz 9 .

La renovación de las fuentes tradicionales alcanza su cénit en la obra lorquiana a raíz de su acercamiento a los movimientos vanguardistas que se estaban desarrollando en la Europa de principios del siglo XX. Aunque Lorca está influenciado en mayor o menor medida por todas las vanguardias ${ }^{10}$, debemos detenernos especialmente en dos movimientos: la poesía pura y el surrealismo.

Blanch (cfr. 1976: 148-149) define a los poetas puros como aquellos que construyen un mundo imaginario entre la intimidad psicológica y la realidad exterior. En este sentido, la poesía pura se presenta vinculada al gongorismo, una corriente propiamente española que ensalza la reinvención poética del cordobés Góngora. En su conferencia «La imagen poética de Don Luis de Góngora», García Lorca destaca que «la originalidad de don Luis de Góngora, aparte de la puramente gramatical, está en su método de cazar las imágenes» (García Lorca, 1954c: 230). Estas palabras están a la base del gran interés por la metáfora de los autores de la Generación del 27.

\footnotetext{
${ }^{8}$ El artículo de Maurer titulado «García Lorca y el arte tradicional: del romancero oral a los ballets russes», incluido en el volumen de Andrés Soria Olmedo La mirada joven. Estudios sobre la literatura juvenil de Federico García Lorca (1997), ahonda en las fuentes musicales de la poesía de Lorca, especialmente en sus obras de tendencia tradicionalista.

${ }^{9}$ Para más información acerca de la influencia de la tradición popular en Federico García Lorca y su labor de dignificación del folclore andaluz recomendamos la lectura del libro de Soria Olmedo Fábula de fuentes. Tradición y vida literaria en Federico García Lorca (2004).

${ }^{10}$ La segunda parte del estudio de Antonio F. Cao Federico García Lorca y las vanguardias: hacia el teatro (1984) analiza magistralmente la influencia de cada uno de los movimientos literarios de vanguardia en la obra lorquiana.
} 
Con respecto al surrealismo, Lorca rechazará en todo momento la idea original de "escritura automática" esbozada por André Bretón. El aspecto del surrealismo que verdaderamente interesa a García Lorca - y que comparte con el creacionismo, el ultraísmo y la poesía pura - es «la supremacía de la imagen, la cual viene a convertirse en el instrumento que salva la antinomia realidad-sueño» (Cao, 1984: 60). Quizás lo realmente relevante de la obra lorquiana no sea el influjo surrealista, sino más bien la construcción de una estética de evasión ( $c f r$. Cao, 1984: 70) ${ }^{11}$.

En definitiva, a pesar de abrazar la particular expresión de las vanguardias europeas en sus obras poéticas y teatrales más tardías, Federico García Lorca jamás ignorará sus raíces culturales y reivindicará, desde un lenguaje surrealista e innovador, la tradición andaluza. Entre todos sus símbolos, la luna es posiblemente el motivo poético más constante a lo largo de su producción literaria. Ya sea desde una concepción romántica o desde su visión neoyorquina de frustración agónica, la luna como metáfora no se desvincula en ningún momento del arraigado folclore regional andaluz.

\section{La luna en las obras de Li Bai y de Federico García Lorca}

La luna es un motivo central en las obras de Li Bai y de Federico García Lorca, a pesar de la lejanía geográfica y cronológica que separa a los dos autores. Es innegable la relevancia de la luna, íntimamente vinculada a la naturaleza, en las tradiciones culturales china y española. Por ello, antes de esgrimir las diferencias en el tratamiento de este objeto celeste, conviene profundizar en las similitudes principales — desde un punto de vista temático y formal- entre la poesía de Li Bai y de Lorca.

Desde una perspectiva temática, la inclusión de la luna en paisajes naturales nocturnos es una constante en ambos escritores. Aunque en la mayoría de ocasiones la luna actúa como una metáfora vinculada a una cuestión más íntima y trascendental, encontramos ejemplos en los que el rol de la luna aparece limitado a una mera figuración del espectáculo nocturno. En este tipo de poemas, en definitiva, la luna tan solo se nombra como parte de una descripción del ambiente, que ayuda a introducir el tema central.

En el caso de García Lorca, esta tesis es especialmente evidente en su primera etapa poética de inspiración romántica. Nos referimos concretamente a su Libro de poemas, obra en la que la luna se presenta estrechamente relacionada con la nocturnidad y expresa sentimientos individuales tan propios del Romanticismo como la tristeza, el ideal, la soledad, la melancolía o la infinitud del alma. Analicemos un ejemplo:

Es la noche de luna menguante.

¡Escuchad! ¿Qué se siente en el cielo, que los grillos refuerzan sus cuerdas y dan voces los perros vegueros? (García Lorca, 1954a: 43).

\footnotetext{
${ }^{11}$ A este respecto, las conferencias de Lorca «Imaginación, inspiración, evasión» (1928) y, especialmente, «Juego y teoría del duende» (1933) son ejemplares para rastrear la influencia surrealista en su teoría estética, así como su concepción de acto creador y de evasión.
} 
En estos versos, extraídos del poema «Santiago», se describe el peregrinaje del apóstol Santiago a través del cielo nocturno. El intrépido peregrino avanza en su camino imbuido por un ambiente romántico que una luna menguante domina. La luna, pues, no es protagonista de la acción, como sí veremos a partir de Canciones, sino que responde a un arquetipo juvenil poco depurado.

En ciertos poemas de Li Bai el rol de la luna es más accesorio si cabe. Insertado en una tradición poética con una larga fijación a la representación de la naturaleza, Li Bai compone algunos escritos en los que la luna es un elemento más de la descripción de un paisaje:

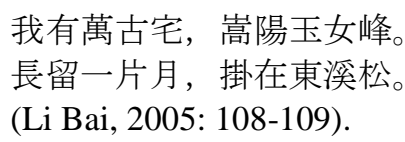

Yo tengo una morada eterna,
el pico Yunü del Songshan.
Allí permanece una luna,
pende de un hilo del torrente.

Este extracto de «Acompaño al ermitaño Yang, que regresa al monte Song» corresponde a una descripción de Songshan, una de las cinco montañas sagradas del taoísmo, a la que el letrado Yang Yan, tras abandonar la función pública, decide retirarse. La función de la luna, en este caso, es meramente anecdótica; si acaso otorga cierto misticismo a la escena.

En relación al contenido, cabe señalar otra de las similitudes entre la obra de Li Bai y García Lorca: el tratamiento de la relación entre el sol y la luna.

孤蘭生幽園, 眾草共黄沒。
雖照陽春暉, 复悲高秋月。
(Li Bai, 2005: 48-49).

Teta roja del sol.

Teta azul de la luna.

Torso mitad coral,

Mitad plata y penumbra (García Lorca, 1954a: 287).
En el hondo jardín crece sola la orquídea, inmersa en la espesura de hierbas silvestres. Por más que la ilumina el sol de primavera también la desconsuela la luna de otoño.

Ahora bien, aunque la luna y el sol se presentan al mismo nivel en ambos poemas — «Poema antiguo XVIII» y «Arlequín»-, la relación que se establece entre los astros es distinta en función del pensamiento tradicional que late detrás de cada cultura. En García Lorca el sol se erige en múltiples ocasiones como antítesis de la luna bajo una concepción dicotómica que mucha relación guarda con la cosmovisión judeocristiana - la luz y la oscuridad como opuestos-. En este poema de su obra Canciones, el sol y la luna se vinculan a la calidez y la frialdad, tanto en relación a los colores como a las emociones evocadas. En cambio, en Li Bai la luna y el sol establecen un nexo de complementariedad asociado a los principios fundamentales yin y yang, respectivamente. El yin está ligado a la oscuridad, el yang a la luminosidad. El pensamiento chino tradicional siempre ha dictado que «no hay verdad absoluta y eterna, sino dosificaciones [...] En lugar de términos que se excluyen, predominan las oposiciones complementarias [...] se pasa del Yin al Yang, de lo indiferenciado a lo diferenciado, por transición imperceptible.» (Cheng, 2002: 31) $)^{12}$

\footnotetext{
12 Teóricamente, el pensamiento chino viene a decir que no existe ni la oscuridad ni la luz en su forma total, sino que se trata de un equilibrio de contrarios. Ahora bien, este fundamento es bastante discutible. En la práctica la dicotomía es real
} 
Desde un punto de vista formal, tanto Li Bai como Federico García Lorca se sirven del epíteto para matizar cualidades de la luna que son asumidas en circunstancias ordinarias, como su redondez o su brillantez. En otras ocasiones, la inclusión de adjetivos amplía el abanico de evocaciones asociadas a la luna. «Luna otoñal» [秋月] (Li Bai, 2005: 60), «luna montañesa» [山月] (130), «luna de antaño» [古詩月] (124), «luna de hogaño» [今月] (124) son algunas de las imágenes que Li Bai introduce en su poesía. García Lorca, por su parte, también adjetiva de forma muy personal el símbolo de la luna: «luna gitana» (García Lorca, 1954a: 400), «media luna» (413), «luna incomprensible» (448) y «luna apuntillada» (505).

Otro aspecto formal muy relevante en la producción literaria de Li Bai y Lorca es el mecanismo de la metáfora. En efecto, muchos de los términos imaginarios que hacen referencia a la luna en la poesía de Li Bai también son empleados, doce siglos más tarde, por Federico García Lorca. Analicemos dos de las metáforas más frecuentes: la luna como escarcha y la luna en tanto que espejo.

床前明月光，疑是地上霜。

(Li Bai, 2005: 132).
Ante mi lecho

la luz de una brillante luna semeja escarcha que cubriera el suelo.

En estos dos primeros versos de «Nostalgia en una noche tranquila» Li Bai ya establece una cópula en la que se identifica la «brillante luna» con la escarcha. La escarcha, a su vez, aparece frecuentemente relacionada con el otoño, el inicio del frío y la decadencia. Además, la escarcha siempre se identifica con el paso del tiempo y la vejez, puesto que su color es el mismo que el de las canas. En este sentido, aunque en «Canto de Qiupu XV» no se nombra explícitamente la luna, la imagen de la escarcha nos retrotrae, por extensión, a una luna otoñal:

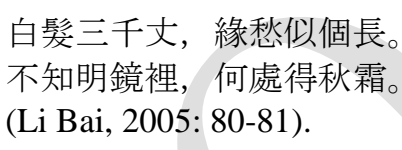

Treinta mil pies miden mis canas, igual de largas son mis penas. En el espejo me pregunto de dónde viene tanta escarcha.

Respecto a Federico García Lorca, aunque la escarcha no hace referencia necesariamente a la luna, sí compone la metáfora de una escena nocturna y aparece vinculada en numerosos casos a las estrellas del firmamento. Esta imagen en Lorca encierra significados diversos: desde lo delicado, lo frágil y lo inconsistente hasta lo frío y lo muerto (cfr. Salazar, 2001: 76). En este sentido, la significación de la escarcha en tanto que imagen de la fugacidad de la vida guarda cierta relación con la obra de Li Bai. He aquí dos ejemplos: «Romance sonámbulo», incluido en Romancero gitano, en el que la escarcha se vincula a esa idea de delicadeza y transparencia, y «Pequeño vals vienés», extraído de Poeta en Nueva York, en el que viene a simbolizar el hielo y lo yerto.

y el elemento yang se ha impuesto frecuentemente sobre el yin. El más claro ejemplo de ello es que lo femenino (yin) siempre ha estado sometido a lo masculino (yang). 
Bajo la misma luna: la simbología de la luna en Li Bai y Federico García Lorca

\author{
Verde que te quiero verde. \\ Grandes estrellas de escarcha, \\ vienen con el pez de sombra \\ que abre el camino del alba (García Lorca, 1954a: 400) \\ Hay un fragmento de la mañana \\ en el museo de la escarcha. \\ Hay un salón con mil ventanas (535).
}

En cuanto a la metáfora del espejo, ambos autores incluyen en algunos poemas un juego de reflejos procedente de la luna, que irradia con su luz el mundo terrenal. Veamos dos ejemplos concretos: «Empuño el vaso y pregunto a la luna» de Li Bai y, de nuevo, «Pequeño vals vienés» de Lorca:

\author{
自如飛鏡臨丹關, \\ 綠煙滅盡清輝發。 \\ (Li Bai, 2005: 124-125). \\ En Viena hay cuatro espejos \\ donde juegan tu boca y los ecos (García Lorca, 1954a: 535).
}

Refulgente espejo, sobrevuela palacios;

extintas las nieblas, irradia esplendor puro.

Una vez analizadas las similitudes en lo que respecta al tratamiento de la luna en ambos autores, damos paso al grueso de nuestro proyecto comparativo: el estudio de los mecanismos de vanguardia y tradición en la obra de Li Bai y de Federico García Lorca.

Ahora bien, es necesario aclarar que la tradición y la innovación no son indisociables en sus respectivas producciones literarias. Por razones pragmáticas se ha tendido a diferenciar una vertiente tradicionalista de una rupturista sin tener en cuenta que, en muchos de sus textos, las dos tendencias confluyen. Especialmente en los escritos más vanguardistas se parte de referencias a la tradición para crear un estilo más personal, ya sea desde un punto de vista formal o temático. Dado que ni siquiera cabe establecer una diferenciación cronológica en dos etapas ${ }^{13}$, la distinción entre tradición y vanguardia con respecto a la luna que a continuación se presenta tan solo persigue una mayor facilidad de comprensión. En cualquier caso, se pondrá en relación ambas tendencias, especialmente en el apartado sobre la vanguardia, en el que rastrearemos la reelaboración rupturista a partir de la tradición cultural propia.

\title{
4. 1. Tradición
}

A continuación, rastrearemos los mecanismos de perpetuación de la tradición en las obras de Li Bai y de Federico García Lorca. Mientras que Lorca dedica muchos esfuerzos para elevar el folclore

\footnotetext{
${ }^{13}$ En el caso de Federico García Lorca, la crítica ha encorsetado su obra poética en dos fases claramente diferenciadas: por un lado, un periodo tradicionalista, representado por Romancero Gitano, y una etapa vanguardista, con Poeta en Nueva York como su máximo referente. Sin embargo, esta distinción es completamente falaz, ya que son solo tres años los que separan la fecha de finalización del primer poemario del inicio del segundo — Romancero gitano (1924-1927) y Poeta en Nueva York (1929-1930)—. La imprecisión de la clasificación es tal que hay obras profundamente tradicionalistas, como Diván del Tamarit (1936), que parecen haber sido gestadas en su mayor parte a lo largo de los años treinta, época en la que se presupone que Lorca estaba inmerso en el surrealismo.
} 
andaluz a una categoría culta, Li Bai solo concibe la tradición como un punto de partida en la creación literaria, así como en la conformación del mito que gira en torno a su persona. Debido al influjo continuo que recibe de la tradición regional en la que se inserta, abordaremos en primer lugar la obra lorquiana. Aunque nuestro estudio se centra en la poesía, analizaremos también de manera breve la presencia del símbolo de la luna en sus obras teatrales.

La luna tal cual la entiende Federico García Lorca admite numerosas significaciones. El autor granadino aprendió del mundo rural que la luna simboliza la muerte. Frente al sol, que se presenta estático y poderoso, la luna es un astro en continua mutación que crece, mengua y desaparece. De hecho, es frecuente encontrar en su obra referencias a los días de lunación, estrechamente ligados a la tradición astrológica. El número tres, por ejemplo, aparece constantemente en la poesía lorquiana por corresponder a una antigua división de las fases lunares (creciente, dominante y menguante), así como por indicar el tiempo de aparente ausencia de la luna en el firmamento. En «Muerte de Antoñito el Camborio» (Romancero gitano) la inclusión del número tres coincide con la trágica muerte del gitano: «Tres golpes de sangre tuvo / y se murió de perfil» (García Lorca, 1954a: 420). En su obra de influencia surrealista Poeta en Nueva York encontraremos incluso con más fuerza los ecos de la tradición folclórica del número tres, como en el poema «Vals en las ramas», en el que no solo representa un ritmo musical de tres por cuatro ${ }^{14}$, sino la inauguración de un nuevo ciclo lunar, coincidente con la huida de una angustiosa Nueva York: «Cayó una hoja / y dos / y tres. / Por la luna nadaba un pez» (537).

El número cuatro, por su parte, posee dos orígenes en el folclore español: las cuatro fases de la luna y el cuarto día de lunación a partir del primer día de luna nueva. En el poema «Murió al amanecer» (Canciones) se evoca una «noche de cuatro lunas» (343), que hace alusión a una muerte derivada de la total desaparición de la luna en su último día de fase decreciente.

La tradición alquimista también aparecerá plasmada en su simbología: mientras que el sol se encuentra vinculado al oro, la luna se representa a través de la plata. En Romancero gitano estas referencias son frecuentes, como en «La casada infiel»: «sin luz de plata en sus copas / los árboles han crecido» (406). También lo serán en su teatro, concretamente en la tragedia Bodas de sangre: «Plata en la cara de la novia» (776).

En definitiva, la luna en Federico García Lorca se trata de un complejo símbolo que, a pesar de estar determinado en todo momento por estas creencias populares relacionadas con la muerte, adquiere ricos matices en cada una de sus obras. Dentro de un mismo poemario es posible encontrar incluso distintas maneras de contemplar la luna.

Una vez superada una etapa juvenil en la que la luna adquiría tintes románticos, Lorca compone Primeras canciones y Canciones, obras en las que se asiste a un acercamiento al astro nocturno, a raíz de una atracción derivada de su presencia inalcanzable en el cielo y la cercanía de su reflejo en el agua.

\footnotetext{
${ }^{14}$ En el compás ternario la parte acentuada cae cada tres pulsos rítmicos. Es común en composiciones como los valses. Lorca pretende recrear esta música característica a través de una estructura rítmica muy marcada: «cayó una hoja / y dos / y tres».
} 
Este planteamiento es evidente en la primera composición de «Nocturnos de la ventana», en la que el individuo consigue familiarizarse con un imposible como la luna a través de un juego de espejos:
Alta va la luna.
Bajo corre el viento.
(Mis largas miradas,
exploran el cielo.)
Luna sobre el agua.
Luna bajo el viento.
(Mis cortas miradas,
exploran el suelo.) (291).

En estos dos libros de canciones la luna simboliza, además, el sentimiento amoroso. En el conjunto «Canciones de luna» (339-348) el surgimiento y la corta duración de una relación amorosa ya fracasada se asimila al ciclo vital. ${ }^{15}$ La atracción amorosa femenina también se vincula a la luna en poemas como «Eco», en el que se combina con el perfumado y femenino olor del nardo: «el nardo de la luna / derrama su olor frío» (372).

Advertimos también en Canciones cómo Lorca vuelca en su forma más pura la vinculación tradicional entre la luna y la muerte. En las dos composiciones tituladas «Canción de jinete» se liga el color negro con el puñal y el color rojo con la sangre, adelantando así la génesis de obras como Bodas de sangre:

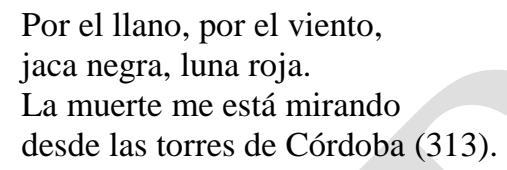

Tras componer Poema del cante jondo, en el que la luna se presenta como depositaria del destino amoroso, Federico García Lorca escribe Romancero gitano, poemario en el que ya se vislumbran las principales significaciones lorquianas de la luna. En «Romance de la Guardia Civil Española» la luna se convierte en testigo de la llegada de la benemérita a lomos de sus caballos y alcanza así su éxtasis contemplativo: «la media luna soñaba / un éxtasis de cigüeña» (427). La luna evocada en el romance «San Gabriel» alude a la fecundidad, tema que se desarrollará con mayor profundidad en la pieza teatral Yerma: «Anunciación de los Reyes / bien lunada y mal vestida» (415). Por su parte, en el poema «Thamar y Amnón» la influencia lunar precipita el incesto de los dos hermanos:

$$
\begin{aligned}
& \text { Thamar estaba soñando } \\
& \text { pájaros en su garganta } \\
& \text { al son de panderos fríos } \\
& \text { y cítaras enlunadas (439). }
\end{aligned}
$$

Ahora bien, si hay dos romances que plasmen a la perfección el protagonismo de la luna en la poesía de Lorca, esos son «Romance de la luna, luna» y «Romance sonámbulo». En el primero de ellos, apunta Correa (1957: 1066), «la luna antropomorfizada en figura de mujer ejecuta una danza

\footnotetext{
${ }^{15}$ Así queda plasmado en el título de los siete poemas «La luna asoma», «Dos lunas de tarde», «Lunes, miércoles y viernes», «Murió al amanecer», «Primer aniversario», «Segundo aniversario»y «Flor».
} 
ritual de la muerte ante el niño gitano que cae prisionero en las redes malignas de la misteriosa danzante»:
La luna vino a la fragua
con su polisón de nardos.
El niño la mira mira.
El niño la está mirando.
[...] Niño, déjame que baile.
Cuando vengan los gitanos,
te encontrarán sobre el yunque
con los ojillos cerrados (393).

En «Romance sonámbulo», por su parte, la influencia entre la luna y la gitana se manifiesta a través de los colores:
[...] verde carne, pelo verde, con ojos de fría plata.
Verde que te quiero verde.
Bajo la luna gitana,
las cosas la están mirando
y ella no puede mirarlas (400).

Aparte de su obra poética, no podemos obviar la obra dramática de Lorca por la importancia incontestable de los símbolos. En Yerma las alusiones a una luna dormida ligan este símbolo con la infecundidad. Yerma, la protagonista, quiere ante cualquier circunstancia ser madre y es este deseo el que le lleva a asesinar a Juan, su marido, que es infértil y no puede hacerle feliz:

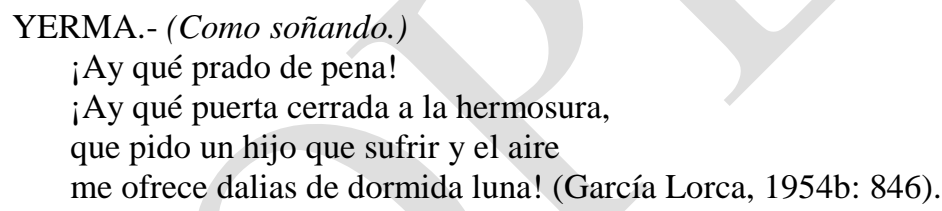

No obstante, es Bodas de sangre la tragedia lorquiana sobre la luna por excelencia. Aparte del continuo influjo de la luna a lo largo de toda la obra, adquiere a partir del primer acto del cuadro tercero una función estructural. La luna se convierte en la verdadera protagonista de la pieza desde la huida de Leonardo y la Novia hasta su encuentro con el Novio. A estas frenéticas escenas le sucede una suerte de ritual en torno a la luna invocado por tres leñadores:

LEÑADOR 1. .-

¡Ay luna que sales!

Luna de las hojas grandes.

LEÑADOR 2. ${ }^{\circ}$--

¡Llena de jazmines la sangre! (775).

El ritual en sí aparece protagonizado por la Mendiga, metáfora de la muerte, y la Luna, que, convertida en personaje, comparte incluso un diálogo con el espectador:

LUNA.- ¿Quién se oculta? ¿Quién solloza por la maleza del valle?

La luna deja un cuchillo 


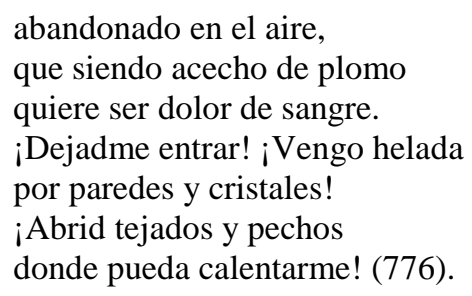

En definitiva, la luna entra en escena tras el quebrantamiento de las normas impuestas por la sociedad. Sedienta de sangre, esta luna divinizada tiene como función iluminar el camino de huida y precipitar la muerte inevitable del amado. Es la luna, pues, la que proclama y confirma la tragedia en Bodas de sangre.

Una vez analizada la simbología de la luna desde la perspectiva de la tradición en Federico García Lorca, damos paso al estudio de la obra poética de Li Bai.

La fugacidad de la vida fue una de las principales preocupaciones de los poetas de la dinastía Tang $^{16}$. La búsqueda de la longevidad se convirtió en una obsesión para muchos hombres que observaron cómo la naturaleza seguía intacta mientras ellos estaban abocados a la muerte. La naturaleza inmanente se contrapone así a una naturaleza fugaz (por ejemplo, las flores que se marchitan). La luna, en tanto que símbolo constante a lo largo de toda la tradición literaria china, está ligada a esta inmanencia natural y, por consiguiente, a la inmortalidad. Es por ello que muchos autores de Tang compondrán poemas a la luna, que alumbra a todos los seres que habitan la tierra en un tiempo eterno, es decir, en el pasado, el presente y el futuro.

Entre todos ellos Li Bai es probablemente el poeta que más canta a la luna, aunque la mayoría de sus composiciones difieren del simbolismo asociado por el canon literario chino hasta el momento ${ }^{17}$. Sin embargo, podemos rastrear en la producción de Li Bai algunos poemas que perpetúan de manera fidedigna la tendencia tradicional.

En la poesía china anterior la luna había sido concebida en muchos casos como símbolo del hogar y de la unión con aquellos que están separados. Estas canciones de añoranza, muy vinculadas al Festival de Medio Otoño ${ }^{18}$, ponen en relación el yo poético con la persona a quien se echa de menos por razones de lejanía geográfica.

Li Bai ha compuesto varios poemas bajo esta temática, que posee unos códigos muy estrictos. «Pensamiento en una noche tranquila» es un claro ejemplo de ello:

\footnotetext{
${ }^{16} \mathrm{Si}$ se desea profundizar en el contexto de la poesía de la dinastía Tang y las características de los diversos autores que la componen, recomendamos encarecidamente el capítulo «Poetry of the T'ang dynasty» incluido en el manual The Columbia History of Chinese literature (2001), editado por Victor H. Mair.

${ }^{17}$ Es preciso señalar que, aunque el tratamiento de la luna en la obra de Li Bai fue rupturista, los poetas inmediatamente posteriores a Li Bai no cultivarán el símbolo de la luna bajo su particular visión, sino que optarán por perpetuar la vertiente tradicional que aboga por una gran influencia de la luna sobre el individuo. Podríamos decir que, en cierto sentido, Li Bai conforma un "desvío" en la tradición, lo que le convierte en un espécimen único en la poesía china.

${ }^{18}$ El Festival de Medio Otoño (中秋節Zhongqiujie) es una festividad tradicional china que se celebra el día quince del octavo mes lunar (a lo largo de septiembre). Se organiza en honor a la luna y busca reunir a toda la familia una vez al año, ya que el caracter chino asociado a la luna llena (團圓yuan) está incluido en la palabra “reunión familiar” (團圓tuanyuan).
} 
床前明月光, 疑是地上霜。 舉頭望明月，低頭思故鄉。 (Li Bai, 2005: 62-63).
Ante la cama, contemplo la luna.

Parece escarcha esparcida en el suelo.

Alzo los ojos, la veo en el monte; los bajo y pienso en mi tierra natal.

Aunque en este poema el sentimiento de nostalgia no es aplicado a un ser humano sino a un lugar, la luna sigue simbolizando el hogar, pues la redondez de la luna siempre ha estado vinculada a la perfección y a la unión familiar. Posiblemente este texto se compusiera durante uno de sus exilios, puesto que canta a su tierra natal.

El vino como motivo para expresar la alegría o la tristeza será otro elemento que Li Bai rescate de la tradición y cultive hasta convertirlo incluso en protagonista de sus versos. La tradición del vino como motivo literario se remonta a los poetas Sima Xiangru, a quien ya hemos tratado, y Tao Yuanming (陶淵明) ${ }^{19}$.

El alcohol, en efecto, es una excusa literaria para recrear con una mayor espontaneidad y sinceridad las emociones plasmadas en sus textos. El vino permite a Li Bai olvidarse del pasado y del futuro y consagrarse al presente, a la contemplación poética y a una máxima libertad creativa. El motivo de la copa de vino está, además, estrechamente relacionado con la luna: el vino en la copa refleja la luna y la acerca al yo poético. En definitiva, el alcohol es la única vía de familiarizarse con el astro nocturno y ponerse a su nivel. En «Dedicado a Meng Haoran» advertimos esta obsesiva fijación por el vino y la luna:

\author{
醉月頻中聖，迷花不事君。 \\ 高山安可仰, 徒此揖清芬。 \\ (Li Bai, 2005: 86-87).
}

Borracho de luna, cae presa del vino. Amante de flores, no sirve al señor. ¿Cómo alzar los ojos ante esa eminencia? Tan sólo saludo su pura fragancia.

Esta comunión entre el vino y la luna también es, en cierta medida, atribuida al taoísmo, escuela de pensamiento que influyó decisivamente en los poetas de la dinastía Tang. Apunta Owen (cfr. 1981: 140), no obstante, que la fijación por el taoísmo religioso no es la misma en Li Bai que en otros autores como Wang Wei. A Li Bai no le interesaban del taoísmo ni los principios cósmicos ni la protociencia alquimista, sino los mecanismos de los inmortales para liberar la imaginación. En el poema «Bebiendo solo bajo la luna III» la aspiración por la inmortalidad se conjuga con los motivos del alcohol y la luna:

\begin{abstract}
三月咸陽城, 千花書如錦。 誰能春獨愁，對此徑須飲。 穹通與修短, 造化成所禀。 一樽齊死生, 萬事固難審。 醉後失天地, 西然就孤枕。 不知有吾身, 此樂最為甚。 (Li Bai, 2005: 154-155).
\end{abstract}

Cuando llega el tercer mes en Xianyang, las flores al sol parecen brocado. ¿Quién puede sufrir solo en primavera? En un trance así, beber es vital. Fracaso o fortuna, existencia o fin, Están desde siempre predestinados. Con un vaso se igualan vida y muerte, y no se distinguen las diez mil cosas. Ebrio, pierdo noción de cielo y tierra,

\footnotetext{
19 Tao Yuanming, también llamado Tao Qian (陶潛), es un escritor chino de inspiración taoísta del siglo IV. Durante la dinastía Tang y Song fue emulado por su gran interés por la naturaleza y por su característica voz poética. En sus poemas bucólicos ensalza la libertad que proporciona la vida retirada e inaugura una corriente temática dedicada al vino.
} 
Para concluir analizaremos «Empuño el vaso y pregunto a la luna», quizás el poema de Li Bai que mejor represente la perpetuación de una tradición heredada. En esta composición se da juego el carácter eterno de la luna que conecta al hombre del pasado con el individuo del presente, la respetabilidad que merece este astro -inalcanzable y a la vez cercano gracias al reflejo en el vaso de vino- y la influencia de la luna sobre la humanidad. Estas premisas integran a la perfección la obra de Li Bai en la tradición literaria china y podrían ser en su mayoría aplicables a gran parte de la poesía tradicionalista de Federico García Lorca. Aparte de todo esto, esta composición presenta una referencia al mito chino de Chang'e. Según esta leyenda, Chang'e se refugió en la luna tras robar a su marido el elixir de la inmortalidad. Allí vive acompañado de una liebre que se dedica a preparar el preciado elixir de la vida a partir de sustancias medicinales.

\begin{abstract}
青天有月來幾時? 我今停杯一問之。 人攀明月不可得, 月行卻與人相隨。 皎如飛鏡臨丹閶, 綠煙滅盡清輝發。 但見宵從海上來，寧知曉向雲間沒? 白兔搗藥秋復春, 嫦娥孤棲與誰鄰? 今人不見古時月, 今月曾經照古人。 古人今人若流水, 共看明月皆如此。 唯願當歌對酒時, 月光長照金樽裡。 (Li Bai, 2005: 124-125).
\end{abstract}

\author{
¿Cuánto llevará la luna en el cielo azul? \\ le pregunto hoy, dejando mi libación. \\ En vano pretende el hombre ${ }^{20}$ alcanzar la luna, \\ la luna errabunda, en cambio, acompaña al hombre. \\ Refulgente espejo, sobrevuela palacios; \\ extintas las nieblas, irradia esplendor puro. \\ Se la ve en la noche emergiendo desde el mar, \\ se sabe que al alba se sumerge en las nubes. \\ El conejo hace elixir año tras año. \\ ¿Con quién vivirá la solitaria Chang'e? \\ El hombre de hoy no ve la luna de antaño, \\ la luna de hogaño alumbró al hombre de ayer. \\ El hombre de ayer y el de hoy, aguas que corren, \\ miraron la luna clara, y así fue siempre. \\ Yo sólo deseo que, cuando cante y beba, \\ su luz se refleje eternamente en el vaso.
}

Ahora bien, a pesar de la tendencia tradicionalista de este poema, Li Bai introduce concretamente dos versos que parecen refutar la simbología de la luna en la poesía china anterior: «En vano pretende el hombre alcanzar la luna / la luna errabunda, en cambio, acompaña al hombre». De esta forma, Li Bai invertirá la jerarquía entre los astros y el individuo para subordinar la luna a su yo poético. Esta es la auténtica revolución de Li Bai, en la cual profundizaremos a continuación.

\section{2. Vanguardia}

Li Bai y Federico García Lorca no solo recibieron el influjo de su propia tradición cultural y la perpetuaron de manera magistral, sino que a partir de ella consiguieron crear una voz poética propia.

\footnotetext{
${ }^{20}$ En el texto original se emplea el caracter人 (ren), que literalmente significa "persona”, tal y como traduce Anne-Hélène Suárez. No obstante, cabe señalar que el alter ego poético puede estar refiriéndose con este caracter chino a sí mismo, un uso también frecuente en la lengua china. Esto comulgaría con nuestra tesis sobre el egocentrismo del yo poético de Li Bai, que expondremos más adelante.
} 
Sus innovaciones en el tratamiento de la luna tanto en forma como en contenido les han hecho destacar por encima de otros autores que también han cantado al astro nocturno.

En primer lugar, profundizaremos en los mecanismos vanguardistas en la obra artística de Federico García Lorca. Antes de nada debemos aclarar que, en el caso de Lorca, los significados folclóricos de la luna no se desvinculan por completo de sus obras de tendencia surrealista. Su innovación radica sobre todo en el significante, es decir, en la forma en la que se materializa la luna. Es por ello que procedemos al análisis de un compendio de metáforas y símbolos surrealistas referidos a la luna.

Una de las imágenes más importantes es la vinculación entre la luna y la vaca o el toro, animales que a su vez están íntimamente ligados al mundo de la tauromaquia y a la cogida del torero en una corrida. El poema «Vaca», incluido en Poeta en Nueva York, es un gran ejemplo de ello:

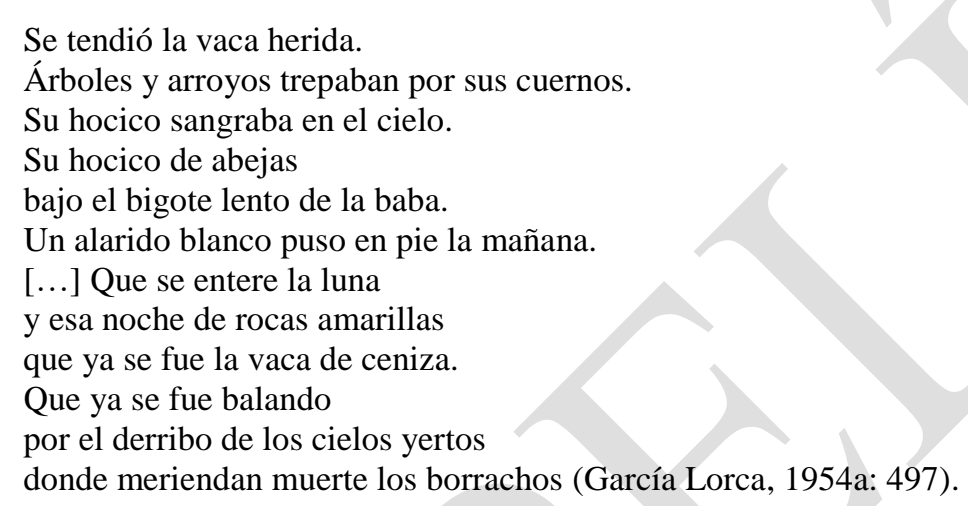

En «Vaca», según Correa (1957: 1067), «la luna ha asumido ya el perfil de una figura mítica de contornos arquetípicos y es identificada con la vaca celeste de concepciones míticas primitivas». En este fragmento concretamente asistimos al descuartizamiento de esta vaca divinizada como si de un banquete ritual se tratase. Este atroz sacrificio se lleva a cabo en dos momentos cúlmenes. En primer lugar, los cuernos, que simbolizan una luna creciente, se pierden en los tintes rojizos de la aurora. En un segundo instante, que coincide con la llegada del amanecer, encontramos plasmados en el cielo los restos del degollamiento de la vaca («su hocico sangraba en el cielo»).

Aunque «Vaca» es el texto que mejor ilustra este simbolismo, el degüello de la res es un motivo recurrente en otros poemas de Poeta en Nueva York. En «Nocturno del hueco» la plaza de toros es el espacio del sacrificio [«En la gran plaza desierta / mugía la bovina cabeza recién cortada» (García Lorca, 1954a: 504)], mientras que en «Cielo vivo» se califica a la luna a través de diminutivos para revelar su impotencia en un ambiente decadente [ «y el rebaño de vacas nocturnas con rojas patitas de muerte» (491)].

Esta equiparación del animal con el astro nocturno característica de Poeta en Nueva York se repite también en el Llanto por Ignacio Sánchez Mejías, en el que la figura arquetípica del toro está al mismo tiempo vinculada a la noción divinizada de la luna en Bodas de sangre. En «Sangre derramada» la luna alumbra la tragedia en torno a la muerte del torero: «La luna de par en par» (553). Al mismo tiempo, la luna, transfigurada en vaca, vela por la víctima, que yace sobre la arena de la plaza. 
En «Cuerpo presente» la «plaza redonda de la luna» (557) es el mar donde conservar la memoria del grandísimo torero. En el mismo poema todavía vemos identificada la luna con el toro para simbolizar la tumba de Sánchez Mejías:

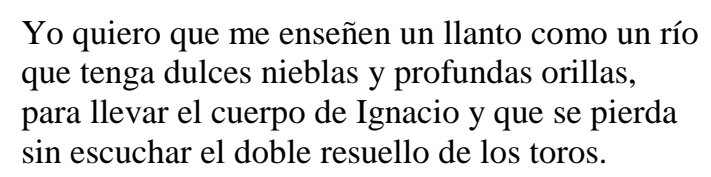

Aparte de esta asimilación entre la luna y la res, otro de los atributos lunares que merece especial atención en Poeta en Nueva York es su condición de dureza (cfr. Correa, 1957: 1081-1082). En «Fábula y rueda de los tres amigos» son numerosas las referencias a la aspereza de la luna: «la luna se pone plana bajo el gallo» (García Lorca, 1954a: 450), «un largo dolor blanco» (451), «la piedra blanca» (451). En el poema «El rey de Harlem» se crea una sensación de frialdad ligada a los materiales como el amianto, que aísla el calor y las llamas: «bajo el amianto de la luna» (460).

Por último, el poema «Crucifixión» (545) supone una revolución formal al combinar imágenes surrealistas de la luna, como la figura de la vaca arquetípica, con la poderosa simbología católica bajo el propósito de magnificar el terrible asesinato de la luna en un firmamento de sangre:

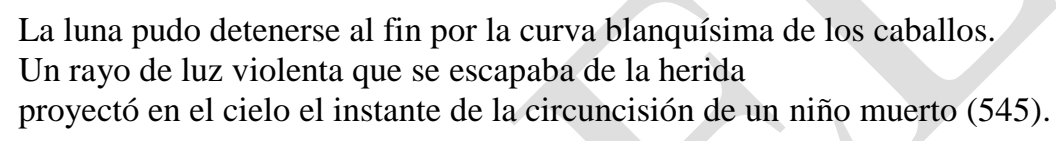

En este primer fragmento, la luna da a luz un niño muerto en mitad de un parto de sangre, es decir, el horizonte está repleto de nubes; no hay luz que alumbre al individuo. El astro agónico arrasa con su debilitado fuego el último resquicio esperanzador del sangriento amanecer («la luna quemaba con sus bujías el falo de los caballos»), quedando así confirmada la tragedia: de la luna queda tan solo una calavera que es observada por tres santas mujeres ( «les enseñaba una calavera por los vidrios de la ventana»). La muerte de la luna divinizada queda proclamada por los fariseos:

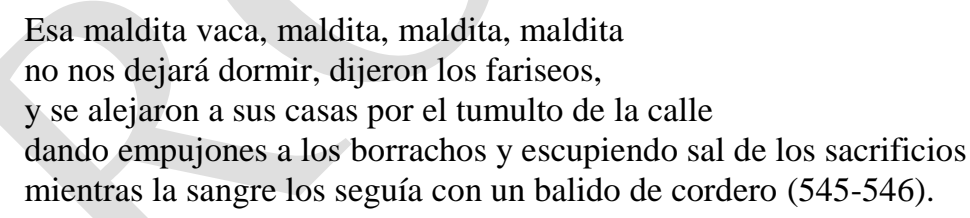

Tras la penetración de una breve luz cósmica en el atardecer, que dota al ambiente de cierto positivismo, los fariseos están obligados a esconderse ante una nueva presencia lunar que recoge el ciclo de muerte y resurrección de la divinidad. El yo poético asume, de esta manera, la muerte por amor como sacrificio litúrgico con el objetivo de hallar de nuevo la armonía en un decadente mundo.

Una vez analizado el compendio de metáforas y símbolos referidos a la luna en su obra de influencia vanguardista, profundizaremos en la única innovación en el contenido vinculada a la luna que advertimos en su obra. Esta novedad temática se puede encontrar en la primera parte de su poemario Poeta en Nueva York. 
Lo característico de esta luna neoyorquina es su ausencia en el firmamento o la pérdida total de su capacidad de atracción, así como la desaparición de su influencia en una realidad desoladora y alejada de lo humano. Todo ello imposibilitará la realización amorosa del individuo y, en consecuencia, se enfrentará, sumido en la soledad, a la negación del propio ser. Solo a partir del grupo de poemas titulados «Huida de Nueva York (Dos valses a la civilización)» habrá un retorno de la noción afirmativa de la luna, como consecuencia del alejamiento de la civilización mecánica neoyorquina. En «Pequeño Vals Vienés» el yo poético recupera la esperanza y vuelve a conjugar la luna con la amada:

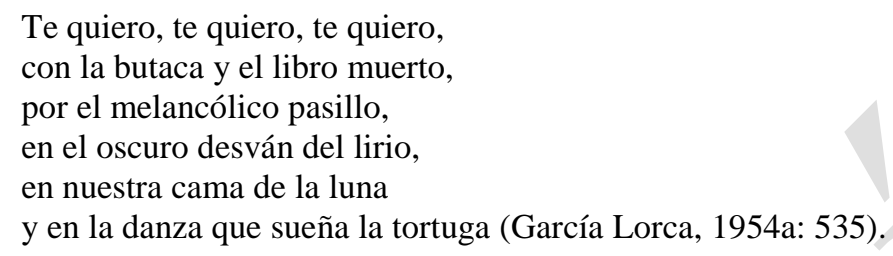

En el «Vals de las ramas» el hombre y la naturaleza se funden de nuevo en un todo en el que la luna volverá a estar presente: «y las ramas desgajadas / se irán bailando con él. / Una a una / alrededor de la luna» (538). Cuando el yo poético llega a Cuba, la luna, imbuida por un ritmo sincopado ${ }^{21}$ característico de la canción cubana, alcanza su máximo esplendor: «Cuando llegue la luna llena / iré a Santiago de Cuba. / Iré a Santiago» (541). Es en este poema titulado «Son de negros de Cuba» donde advertimos por primera vez en Poeta en Nueva York un abandono de la rigidez surrealista y de la temática decadente características de este poemario. En cambio, se abraza de nuevo el folclore, estrechamente vinculado a lo musical, y se alcanza posiblemente uno de los niveles más altos de conjugación entre tradición e innovación formal. Conviven, por tanto, las imágenes vanguardistas («y cuando quiere ser medusa el plátano») y una estructura musical basada en la síncopa propia del son cubano.

Tras estudiar sus poemarios de tendencia vanguardista, nos sumergiremos en su "teatro imposible" ${ }^{22}$. Respecto a su pieza teatral Así que pasen cinco años, identificamos dos manifestaciones principales de la luna: por un lado, la luna es un ideal amoroso contemplativo de difícil acceso y, por el otro, es una suerte de "novia cósmica" al aceptar la celebración de la boda ante la ausencia de la mujer (cfr. Correa, 1957: 1074-1075):

CRIADA. Su novio busca otra cosa. En mi pueblo había un muchacho que subía a la torre de la iglesia para mirar más de cerca la luna, y su novia lo despidió.

NOVIA. ¡Hizo bien!

CRIADA. Decía que veía en la luna el retrato de su novia (García Lorca, 1954b: 539).

\footnotetext{
${ }^{21}$ La síncopa es una estrategia compositiva que persigue la ruptura de la regularidad del ritmo, en este caso a través de la repetición del verso «Iré a Santiago», que se intercala entre versos de mayor longitud.

${ }^{22}$ El "teatro imposible", tal y como lo apodó Federico García Lorca, engloba sus dramas de marcado carácter surrealista, que, según el autor, solo podrán ser entendidos cincuenta años después de su estreno. Las piezas teatrales lorquianas que se agrupan bajo esta denominación son El público, Así que pasen cinco años y Comedia sin título.
} 
No podemos concluir nuestro análisis sin mencionar la obra El público, en la que la luna es un símbolo más que contribuye a urdir esa profunda reflexión sobre la identidad y la homosexualidad que está a la base de la pieza:

FIGURA DE PÁMPANOS.- [...] Si tú te convirtieras en pez luna, yo te abriría con un cuchillo, porque soy un hombre, porque no soy nada más que eso, un hombre, más hombre que Adán, y quiero que tú seas aún más hombre que yo. Tan hombre que no haya ruido en las ramas cuando tú pases. Pero tú no eres un hombre. Si yo no tuviera esta flauta, te escaparías a la luna, a la luna cubierta de pañolitos de encaje y gotas de sangre de mujer (612).

Una vez analizadas las innovaciones vanguardistas en el tratamiento de la luna - principalmente en el terreno formal - llevadas a cabo por García Lorca, estudiaremos en profundidad la revolución que supuso la obra de Li Bai para la poesía china.

Para comprender mejor la desviación tradicional del significado de la luna en la obra de Li Bai retomamos el poema «Empuño el vaso y pregunto a la luna» (vid supra: 4.1.). Recordemos que las referencias al mito de Chang'e, al carácter trascendente de la luna y a su labor de acompañamiento del individuo solitario vinculan este texto a la simbología tradicional de la poesía china. No obstante, hacia el final del poema, Li Bai subordina la luna al yo poético y no al contrario, como se observa recurrentemente en la tradición poética anterior. Con tan solo dos versos [ «En vano pretende el hombre alcanzar la luna / la luna errabunda, en cambio, acompaña al hombre» (Li Bai, 2005: 125)] pone en tela de juicio la tradicional inaccesibilidad de la luna y dota al yo poético de una influencia determinante en el universo.

En el poema «Pensamiento en una noche tranquila», que anteriormente hemos analizado (vid supra: 4.1.), advertimos una conjugación entre la tradición clásica perpetuada y la vanguardia temática: «alzo los ojos, la veo en el monte / los bajo y pienso en mi tierra natal» (Li Bai, 2005: 63). Si bien la luna todavía simboliza el hogar, en este caso el reflejo de la luna tan solo es un recordatorio de la soledad del yo poético.

La innovación en contenido que se le atribuye a Li Bai se debe especialmente a equipararse a sí mismo a la luna, astro al que, desde la lejanía, el yo poético siempre había considerado un objeto digno del más alto respeto y veneración. En ciertos poemas de Li Bai, pues, es el hombre el que influye a la luna y el que moldea su comportamiento, y no a la inversa. En el siguiente ejemplo, extraído del poema «En la puerta oriental de Lu, en barca», reparamos un acercamiento a la luna de un alter ego navegante ${ }^{23}$ a través del reflejo en el agua, que le permite flotar sobre el propio astro:

\section{若教月下乘舟去，何菑風流到剡溪?} (Li Bai, 2005: 118-119)
La barca leve flota a la luna, gira siguiendo el torrente, ¿paseo acaso tras la nevada en la umbría de la montaña?

En otras ocasiones, la influencia entre el ser humano y la luna es recíproca, como en «Día nueve, bebiendo en el Monte Dragón»:

\footnotetext{
${ }^{23}$ En muchos poemas chinos no se explicita el sujeto de la acción, por lo que no podemos concluir si se refiere a sí mismo o al conjunto de seres humanos. Anne-Hélène Suárez, ha preferido introducir en la traducción la primera persona del singular, posiblemente porque es consciente del carácter ególatra del yo poético que crea Li Bai en su obra.
} 
醉看風落帽, 舞愛月留人。 (Li Bai, 2005: 132-133).
Borracho miro el gorro que se lleva el viento, bailar me gusta a la luna, que me retiene.

No obstante, en la mayoría de poemas el yo poético es el sujeto de la acción, mientras que la luna es tan solo el objeto, se deja moldear según los designios del individuo. «En Taiyuan, a principios de otoño»y «Bebo solo» son dos buenos ejemplos de ello:

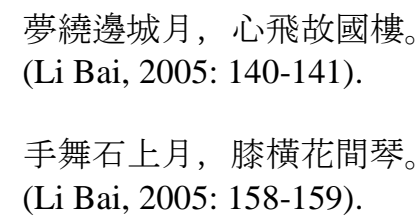

En sueños rodeo la luna fronteriza, en pensamientos vuelo a la tierra natal.

A la luna danzo sobre las rocas, mi cítara taño en medio de flores.

Ahora bien, es el conjunto de poemas titulado «Bebiendo solo bajo la luna» el que mejor evidencia nuestra tesis sobre la inversión de la jerarquía en la contemplación de la luna por parte del yo poético. Analizaremos en profundidad el primero de los poemas por ser el más representativo de los que componen el grupo:

\begin{abstract}
花間一壼酒，獨酌無相親。 舉杯邀明月，對影成三人。 月既不解飲, 影徒隨我身。 暫伴月將影, 行樂須及春。 我歌月徘徊, 我舞影零亂。 醒時同交歡，醉後各分散。 永結無情遊，相期邀雲漢。 (Li Bai, 2005: 150-151)
\end{abstract}

Entre flores, una jarra de vino.

Bebo solo, sin compañía alguna.

Alzo el vaso, invito a la luna clara.

Con mi sombra, ya somos tres personas.

Mas la luna no es capaz de beber;

y mi sombra, tan sólo de seguirme.

Compañeras fugaces, luna y sombra,

disfrutad mientras sea primavera.

Cuando canto, la luna se pasea;

cuando bailo, mi sombra se alborota.

Yo sereno,

nos divertimos juntos;

ya borracho, cada cual por su lado.

Mis eternas amigas insensibles,

os doy cita en el Río de las Nubes.

En «Bebiendo solo bajo la luna I», el yo poético alza su copa de vino a la luna, la personifica y se dirige directamente a ella, como si de una amiga se tratase. La revolución de Li Bai radica en la ausencia de esa reverencia que se presupone en una situación de acercamiento a un ente jerárquicamente superior. En su lugar, el yo poético tiene el pleno control de la situación e invita a la luna a acompañarle en su soledad. Partiendo de una equidad aparente entre astro e individuo, el hombre se alza como el ser más extraordinario de los que protagonizan la escena. A través de un juego de luces y sombras Li Bai concibe a su alter ego como un imán que atrae todo lo que le rodea; es el auténtico centro del universo poético: «mas la luna no es capaz de beber / y mi sombra, tan sólo de seguirme» (151). De esta forma, cualquier acción que emane del yo poético conlleva unas consecuencias en el mundo natural: «cuando canto, la luna se pasea / cuando bailo, mi sombra se alborota» (151).

En definitiva, el yo poético que compone Li Bai se ve a sí mismo como una deidad que se sitúa jerárquicamente por encima del mundo terrenal, de todo objeto sensible. Los dos últimos versos subrayan ese concepto divinizado de individuo: «mis eternas amigas insensibles / os doy cita en el Río 
de las Nubes». Todo ello nos confirma la personalidad hedonista y narcisista del yo poético creado por Li Bai, que a menudo se suele asociar a su propia biografía. Esta asimilación contribuye en gran medida a construir el mito de la inmortalidad que ha rodeado durante siglos a la figura de Li Bai.

A este respecto, es necesario añadir que la ascensión al mundo celestial se logra a través del consumo de alcohol como intermediario. Es por ello que en todo poema de Li Bai en el que se quebranta ese orden jerárquico entre la naturaleza y el individuo se hace referencia a la borrachera del yo poético. La soledad y el vino, por tanto, dotan a estos textos de cierta inmediatez y subjetividad, lo que permite intensificar la sensación de soledad del individuo en relación con la sociedad, así como crear a través de la personificación una presencia natural que lo acompaña —en este caso, la luna-.

Ahora bien, de la misma manera que la embriaguez eleva el yo poético a la categoría de la luna, la sobriedad puede poner fin a esta ilusión. No hay, pues, nada de trascendental y permanente en esta relación entre el astro y el hombre. Mientras en la tradición china anterior o incluso en la poesía de Federico García Lorca advertimos —además de una gran veneración por la luna - un sentimiento de trascendencia en el influjo de lo natural sobre la vida humana, en la poesía de Li Bai todo ello es superfluo y finito.

El vínculo que establece el yo poético con la luna, en resumen, está determinado por la misma acción humana y es consecuencia de un instante efímero de embriaguez. «Un día de primavera, al levantarme después de la borrachera» confirma el control del individuo sobre el mundo natural:

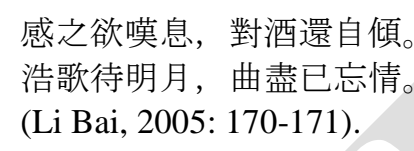

感之欲嘆息，對酒還自傾。 (Li Bai, 2005: 170-171).
La emoción casi me hace suspirar, mas me sirvo de nuevo, frente al vino. Esperando la luna, canto a voces; al acabar olvido el sentimiento.

En conclusión, la revolución temática de Li Bai se basa en la alteración del vínculo tradicional entre la luna y el ser humano. En la tradición literaria china ${ }^{24}$ y en la obra de Federico García Lorca es la luna la que, mediante su influjo, se acerca al hombre y repercute en sus actos. En la poesía de Li Bai, en cambio, la jerarquía no viene dada por el cielo nocturno, sino que el yo poético se eleva y diviniza para equipararse a la luna en un primer momento y, luego, superarla en importancia.

\section{我似麃鴣鳥，南遷懶北飛。 \\ 時尋漢陽令，取醉月中歸。 \\ (Li Bai, 2005: 176-177).}

\author{
Yo me parezco a las aves perdices \\ que al sur emigran, reacias al norte. \\ A veces vengo, cuestor de Hanyang, \\ para embriagarme y volver con la luna.
}

\footnotetext{
${ }^{24}$ Para conocer mejor las diferencias en el tratamiento de la luna entre la poesía de Li Bai y la tradición literaria china se recomienda la lectura de Soroka titulada «Bright moon: the cosmos' role in Chinese poetry» (2011). En este estudio compara poemas de Li Bai y de Su Shi, poeta posterior de la dinastía Song, que perpetúa la poesía tradicional dedicada a la luna.
} 


\section{Conclusiones}

Tras nuestro análisis comparativo entre la poesía de Li Bai y la obra de Federico García Lorca a partir de la luna como símbolo literario, podemos extraer una serie de conclusiones.

En primer lugar, reafirmamos nuestra tesis inicial sobre la recurrencia del tópico de la luna en la obra literaria de artistas procedentes de lugares geográficos diversos e insertos en diferentes épocas históricas. A pesar de la problemática derivada de la gran distancia temporal y cultural que separa a los dos autores de nuestra comparación, el análisis de la simbología de la luna en sus obras nos ha servido para profundizar en los mecanismos de perpetuación de sus respectivas tradiciones literarias y en las formas de innovación respecto a la literatura anterior.

En lo que concierne a los autores a la luz de su contexto histórico-literario, cabe comentar, por una parte, la genialidad de Li Bai. A partir de un sólido conocimiento de su tradición, Li Bai se dedica a cultivar el llamado estilo antiguo (gushi) y a edificar al mismo tiempo su voz poética propia, basada en los conceptos de imaginación ficcional, inmediatez y alusión. Gracias a estos mecanismos, Li Bai genera en el lector una sensación de espontaneidad y consigue introducir su visión subjetiva del pasado literario.

Por otra parte, Federico García Lorca reivindica desde sus inicios la esencia del cante jondo, es decir, las raíces del arte primitivo andaluz. Toda su obra persigue la dignificación y elevación del folclore regional a una categoría supranacional. Sin abandonar su compromiso con la tradición, Lorca, influido por las vanguardias europeas del siglo XX, innova formalmente la poesía española contemporánea, especialmente en el terreno de la metáfora y el símbolo.

Centrándonos en el análisis comparativo propiamente dicho, extraemos tres aseveraciones principales. En primer lugar, subrayamos la artificialidad de la dicotomía entre tradición y vanguardia que se toma de base para estudiar las obras de autores como Li Bai o García Lorca. A lo largo de todas sus obras confluyen las tareas de conservación de la tradición y de creación de una voz poética propia a partir de unos mecanismos de innovación, ya sean temáticos o formales.

En segundo lugar, concluimos que las significaciones de la luna en Federico García Lorca, aunque abundantes, son prácticamente constantes en toda su producción literaria. La luna es vista en todas sus etapas como un objeto trascendente, digno de veneración y determinante para la vida humana. $\mathrm{Su}$ revolución respecto a la tradición anterior radica, por tanto, en la multiplicación de significantes. Bajo el influjo del surrealismo, las metáforas referidas a la luna se vuelven más dispares y, por consiguiente, más complejas. Advertimos, por tanto, un oscurantismo retórico que dota de mayor profundidad a la luna en tanto que referente.

Por último, afirmamos que la innovación simbológica de la luna en la poesía de Li Bai es esencialmente temática. Frente a una tradición literaria que presenta a la luna como un objeto celeste inaccesible y respetable, Li Bai crea un yo poético que maneja la luna y la naturaleza a su antojo. Esto resulta de la inversión de una jerarquía tradicional que presupone que el astro está por encima del mundo terrenal. El alter ego de Li Bai, pues, se eleva a sí mismo a través del vino y, en un afán de superioridad narcisista, se diviniza. 
En conclusión, mientras Federico García Lorca mantiene esa actitud de reverencia y respetabilidad ante la luna que ha dominado durante siglos tradiciones literarias muy diversas, la obra poética de Li Bai supone una auténtica revolución al poner en tela de juicio la influencia del astro nocturno sobre el individuo y al erigir al ser humano por encima de lo que siempre ha anhelado.

\section{Referencias bibliográficas}

ARISTÓTELES (1976): El arte poética. Trad. J. Goya y Muniain. Madrid, Espasa-Calpe.

BLANCH, Antonio (1976): La poesía pura española. Madrid, Gredos.

BOKENKAMP, Stephen R. (1989): «Chinese Metaphor again: Reading-And Understanding-Imagery in the Chinese Poetic Tradition», Journal of the American Oriental Society, 109/2, pp. 211-221.

CAO, Antonio F. (1984): Federico García Lorca y las vanguardias: hacia el teatro. Madrid, Tamesis. CHENG, Anne (2002): Historia del pensamiento chino. Barcelona, Bellaterra.

CorreA, Gustavo (1957): «El simbolismo de la luna en Federico García Lorca», PMLA, 72/5, pp. 1060-1084.

GARCíA LORCA, Federico (1954a): Obras completas. Verso. Ed. A. Del Hoyo. Madrid, Aguilar. (1954b): Obras completas. Teatro, cine, música. Ed. A. Del Hoyo. Madrid, Aguilar. (1954c): Obras completas. Prosa, dibujos. Ed. A. Del Hoyo. Madrid, Aguilar.

KAO, Yu-Kung - MEI, Tsu-Lin (1978): «Meaning, metaphor and allusion in T'ang poetry», Harvard Journal of Asiatic Studies, 38/2, pp. 281-356.

Kroll, Paul W. (2001): «Poetry of the T'ang dynasty», en V. H. MAIR, ed., The Columbia History of Chinese literature. Nueva York, Columbia University Press.

Li BAI (2005): A punto de partir. 100 poemas de Li Bai. Trad. A. H. Suárez. Valencia, Pre-textos.

LisCOMB, Kathlyn (2010): «Li Bai drinks with the moon: the cultural afterlife of a poetic conceit and related lore», Artibus Asiae, 70/2, pp. 331-386.

MAURER, Christopher (1997): «García Lorca y el arte tradicional: del romancero oral a los ballets russes», en A. SORIA, ed., La mirada joven. Estudios sobre la literatura juvenil de Federico García Lorca. Granada, Universidad de Granada, pp. 43-62.

OwEN, Stephen (1981): The great age of Chinese poetry. The High T'ang. Binghamton, Yale University Press.

Platón (2015): República. Trad. J. M. Pavón y M. Fernández-Galiano. Madrid, Alianza.

RELINQUE, Alicia (2005): «Fundamentos de la literatura china», en Literatura china. Barcelona, Universitat Oberta de Catalunya, pp. 5-35.

Ricoeur, Paul (1980): La metáfora viva. Trad. A. Neira. Madrid, Cristiandad.

SAlAZAR, Javier (2011): «Rocío y escarcha: Dos símbolos afines y contrapuestos en la obra de Federico García Lorca», Revista Hispánica Moderna, 54/1, pp. 63-79.

SORIA, Andrés (2000): Federico García Lorca. Madrid, Eneida. 
(2004): Fábula de fuentes. Tradición y vida literaria en Federico García Lorca. Madrid, Amigos de la Residencia de Estudiantes.

SOROKA, Anthony (2011): Bright moon: the cosmos' role in Chinese poetry. Nueva Jersey, Princeton University [tesina].

VARSANO, Paula M. (1992): «Immediacy and allusion in the poetry of Li Bo», Harvard Journal of Asiatic Studies, 52/1, pp. 225-261.

WALSH, John K. (1991): «A Genesis for García Lorca’s Bodas de Sangre», Hispania, 74/2, pp. 255261.

WANG Nian En (1992): The Xing: a comparative approach to Chinese theories of the literary symbolic. Warwick: The Graduate School of Comparative Literature and Literary Translation, University of Warwick [tesis doctoral].

YEH, Michelle (1987): «Metaphor and Bi: Western and Chinese poetics», Comparative Literature, 39/3, pp. 237-254.

YU, Pauline (1981): «Metaphor and Chinese poetry», Chinese Literature: Essays, Articles, Reviews (CLEAR), 3/2, pp. 205-224.

(1987): The Reading of imagery in the Chinese poetic tradition. Nueva Jersey, Princeton University Press. 